\title{
Improvement of the cost-benefit analysis algorithm for high-rise construction projects
}

\author{
Andrey Gafurov ${ }^{1}$, Oksana Skotarenko ${ }^{1}$, and Vladimir Plotnikov², \\ ${ }^{1}$ Murmansk Arctic State University, 15 Kapitana Yegorova str., Murmansk, Russia, 183038 \\ ${ }^{2}$ Saint-Petersburg State University of Economics, 21 Sadovaya str., St. Petersburg, Russia, 191023
}

\begin{abstract}
The specific nature of high-rise investment projects entailing long-term construction, high risks, etc. implies a need to improve the standard algorithm of cost-benefit analysis. An improved algorithm is described in the article. For development of the improved algorithm of costbenefit analysis for high-rise construction projects, the following methods were used: weighted average cost of capital, dynamic cost-benefit analysis of investment projects, risk mapping, scenario analysis, sensitivity analysis of critical ratios, etc. This comprehensive approach helped to adapt the original algorithm to feasibility objectives in high-rise construction. The authors put together the algorithm of cost-benefit analysis for high-rise construction projects on the basis of risk mapping and sensitivity analysis of critical ratios. The suggested project risk management algorithms greatly expand the standard algorithm of cost-benefit analysis in investment projects, namely: the "Project analysis scenario" flowchart, improving quality and reliability of forecasting reports in investment projects; the main stages of cash flow adjustment based on risk mapping for better cost-benefit project analysis provided the broad range of risks in high-rise construction; analysis of dynamic cost-benefit values considering project sensitivity to crucial variables, improving flexibility in implementation of high-rise projects.
\end{abstract}

\section{Introduction}

The problems of evaluation of high-rise construction projects in Russia are relevant. This is largely due to the fact that in Russia high-rise construction is still poorly developed. Therefore, project, economic, technological and other solutions are not sufficiently typified. In our country, houses taller than 75 meters are recognized as high-rise. There are almost 3 thousand of them in the country. At the same time, a little more than 100 buildings with a height of more than 100 meters have been built, over $80 \%$ of them are located in Moscow. As the experience in the construction of high-rise buildings shows, their cost compared with conventional facilities is about $25 \%$ higher. This increase is due to more expensive engineering systems, complex fire-fighting systems, the use of thicker structures, etc. In addition, the design and construction of high-rise buildings takes longer. This also leads to higher costs for such projects due to higher costs for servicing loans.

\footnotetext{
*Corresponding author: plotnikov_2000@mail.ru
} 
These factors make it necessary to develop special methods of cost-benefit analysis for highrise construction projects. In order to evaluate the overwhelming majority of Russia-specific investment projects, a number of methods are used on the basis of dynamic values and the discounted cash flow model (DCF) [1, p. 215]. However, the specific nature of high-rise investment projects entailing long-term construction, high risks, etc. implies a need to improve the standard algorithm of cost-benefit analysis.

\section{Methods}

The authors used different methods: weighted average cost of capital (WACC), dynamic cost-benefit analysis of investment projects (NPV, IRR, PI, DPP, etc.), risk mapping, scenario analysis, sensitivity analysis of critical ratios, etc. These methods were used to evaluate high-rise construction projects.

\section{Results}

Putting together an algorithm of cost-benefit analysis for high-rise construction projects on the basis of risk mapping and sensitivity analysis of critical ratios. A typical algorithm of cost-benefit analysis for construction projects comprises the following main stages:

- forecasting reports and projected cash flow;

- background for a discounted cash flow rate;

- calculation of dynamic cost-benefit values.

Nowadays, there exists a certain academic consensus on the range of methods to be used at every stage of the algorithm. The main methods include the following:

- methods of providing a background for a discounted rate (cumulative risk premium assessment, weighted average cost of capital (WACC), etc.) [3, p. 113-120];

- dynamic cost-benefit analysis of investment projects (NPV, IRR, PI, DP, etc) [5, p. 216223].

In the Russian practice, a similar algorithm is used for high-rise construction projects as well. However, high rise construction is characterised by a number of specific features that may include:

- dependence of project planning on real estate market cycles and market trends;

- significant fluctuations in the scope and structure of project expenses;

- dependence of investment projects on scopes of long-term obligations [9, p. 45];

- lengthy term for a new product (plot selection, topographic and geodesic surveys, design and approval, construction, related infrastructure and landscaping, etc.) [6];

- considerable expenses and highly complex engineering geology survey [2];

- technical complexity of project implementation;

- high variety of risks in such projects.

The combination of the above project-specific features in high-rise construction determines a systemic occurrence of various problems in implementation of the standard algorithm, mostly related to insufficient connection between separate stages of the algorithm.

In order to provide a better reasoning, we need to review the core problems of implementation and probable solutions at every stage of the standard algorithm.

The first stage, "Forecasting reports and projected cash flow", should take into account that high-rise construction projects imply a considerably more varied (in comparison with standard investment projects) range of cash flows that includes [9, p. 52]:

- income from long-term assets;

- income from maintenance;

- income from capital investment; 
- income from transactions;

- selling long-term assets.

The considerable variety of cash flow types in combination with a great influence of a broad range of risks requires cash flow adjustment using risk management methods. Modern risk management approaches towards investment projects imply risk management during project implementation and operation [7, p. 864]. However, separating the algorithm of costbenefit analysis in high-rise construction projects requires a more concise project-specific method.

The risk mapping method (based on preliminary risk identification and assessment) [4, p. 152] may become crucial in this situation, but in implementation of high-rise construction projects there are many various risks that are systematic yet differing in their significance and therefore impact at different project stages (currency rate fluctuation, increasing construction costs, falling demand, etc.). So, to avoid ambiguity, it is reasonable to map risks for each stage of a high-rise construction project, determining risk boundaries for each map separately.

To provide a background for a discounted cash flow rate in an investment project at the second stage of cost-benefit analysis in a high-rise construction project, it is reasonable to take into account that, in cost-benefit analysis of any project, there is an issue of coordinated use of methods in risk assessment (to adjust the projected cash flow) and discounted rate assessment (to calculate the project capital accurately). A lack of coordination between these methods leads, first, to discrepancies in assessment of the same risks with different methods, and secondly, to redundant acknowledgement of those risks.

The lengthy time of high-rise construction projects, high dependence of such projects on capital scope and cost, and other risk exacerbate this lack of coordination. To minimise and exclude those errors, it is reasonable to specify the risks to be identified with each of the methods:

- during risk mapping, it is reasonable to assess influence of all risks at each project stage, except the risk of changes in the cost of capital;

- risks of changes in the cost of capital (during determining a discounted rate).

This approach will significantly reduce the number of methods to provide a background for a discounted rate, which, given the complexity of high-rise construction projects, will significantly simplify the calculation. In a situation when most high-rise construction projects require involvement of various stakeholders and a significant share of borrowed capital, the method of weighted average cost of capital (WACC) may be crucial for developing a background for the discounted rate, with bank loan interest rates, inflation levels, etc. being the main parameters for determining it [3, p. 162].

The method of weighted average cost of capital is applied to high-rise construction projects as follows:

- the project is financially isolated but it is being under consideration while a funding source is not yet determined;

- it is a high-risk project affecting a scope and structure of funding.

However, it is typical of most major high-rise construction to be economically isolated (several commercial findings, assets, and financing structure) and led to a detailed evaluation. Stakeholders, their repayment schedule from their cash flow and assets, and their interest and commitment are supposed to be known. It makes a weighted average cost of capital appear inaccurate. For a more accurate way to predict a remaining cash flow and its discount, it is reasonable to calculate a cash flow and its discount by both equity rate (ER method) and expenses from the equity rate and income on equity (Fig. 1). 


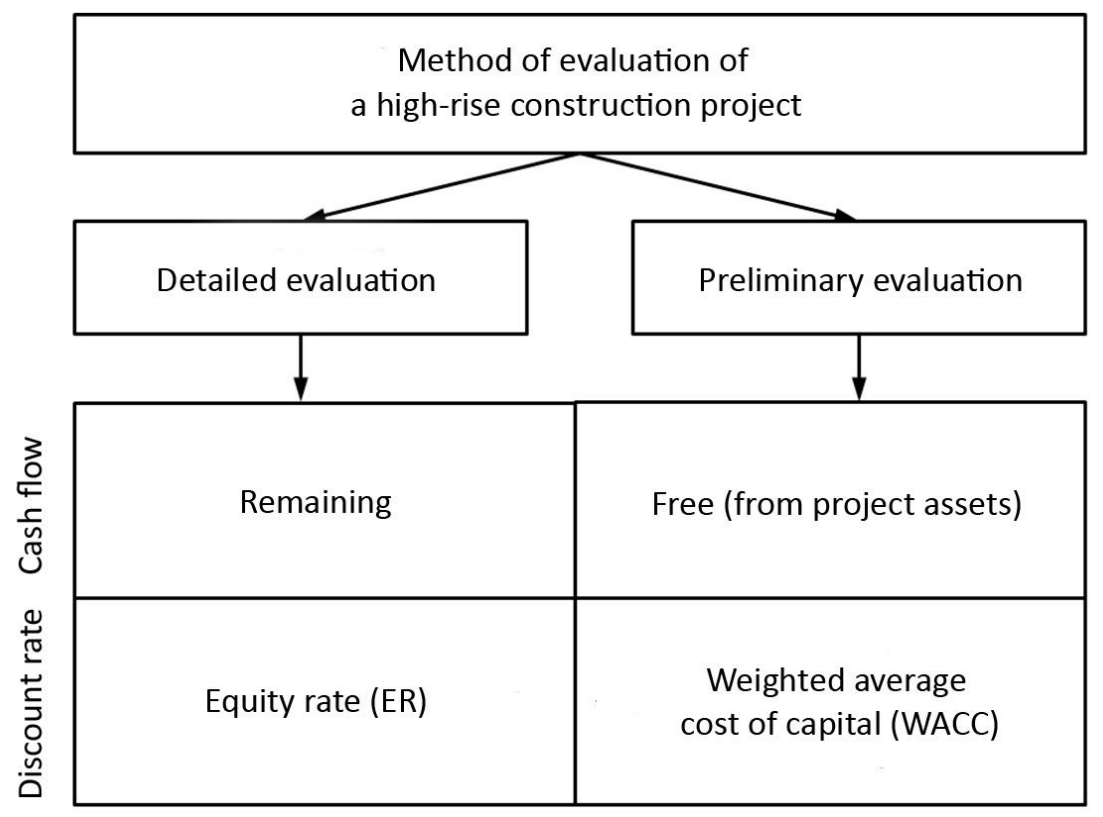

Fig. 1. Methods of evaluation of a high-rise construction project

At the third stage, during calculation of dynamic cost-benefit values, it is necessary to take into account that implementation of high-rise construction projects is connected with a significant scope and variety of risks during the project cycle [7, p. 841]. Specifically, the scope and complexity of such projects determine presence of various groups of risks:

- a broad group of external risks (political and economic crises, competition, economic situation, customs fees, etc.);

- prevalence of risks with a large scope and/or high probability of expected loss, etc.;

- a broad group of changes in internal project parameters (fixed and variable expenses, scope of capital expenses, etc.).

The presence of significant external factors (sectoral, administrative, legal, environmental and other risks) requires including project scenario analysis into the standard cost-benefit analysis (including the "with-project" and "without-project" analysis as a specific case of the method) (Fig. 2).

Additionally, it is reasonable to use the method of sensitivity analysis of critical ratios for more precise assessment of internal risks in high-rise construction projects [8, p. 144-147]. The core variables in analysis of high-rise construction projects are annuals sales of high-rise construction facilities, prices per square metre, variable expenses per square metre, fixed costs of building a high-rise facility, corporate tax rates, initial investment costs and implementation time of a high-rise construction project.

Tables 1-3 show results of an analysis of a typical high-rise construction project. The sensitivity was based on rational ranges or dependencies [3, p. 236-237].

The factors of the first zone (I) require a deeper risk investigation, since they are most NPV-sensitive and least predictable. The factors of Zone II require specific attention during a construction project (that is why every crucial factor is supposed to be calculated). Zone III is least risky and not subject to further consideration. 

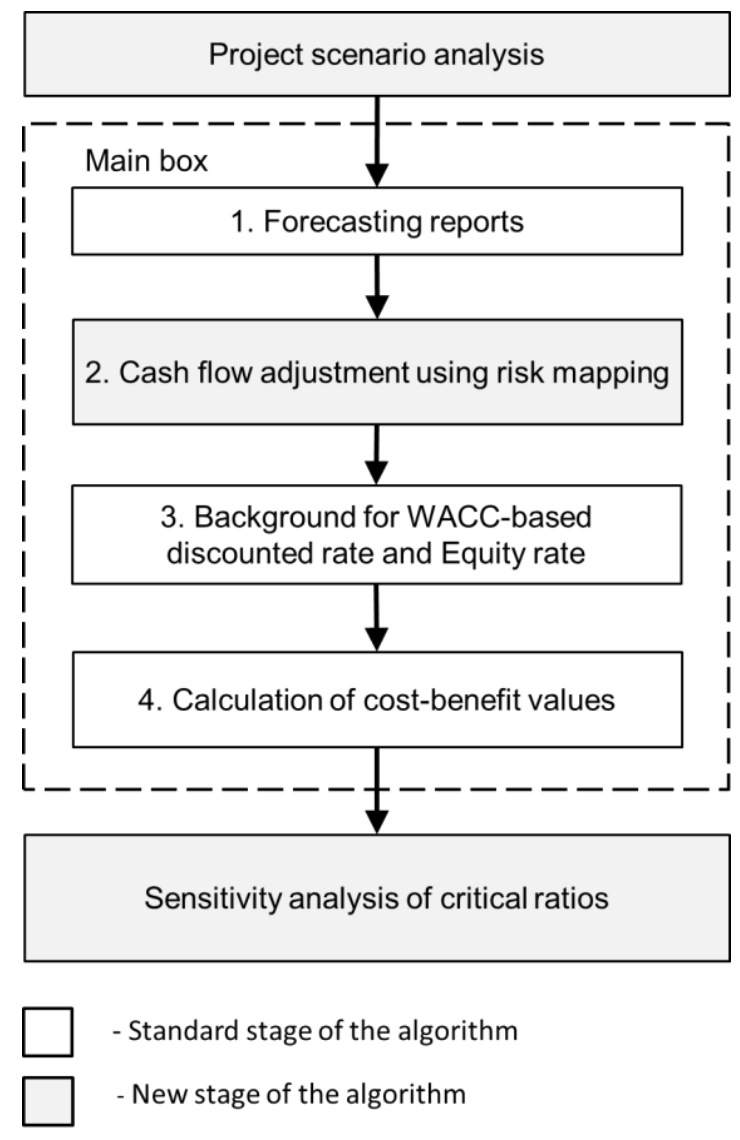

Fig. 2. Cost-benefit analysis algorithm for high-rise construction projects.

Table 1 - Rating key risk-based high-rise construction factors

\begin{tabular}{|l|c|c|c|c|}
\hline Variable (X) & $\begin{array}{c}\text { Variation } \\
\text { X, \% }\end{array}$ & $\begin{array}{l}\text { Variation } \\
\text { NPV, \% }\end{array}$ & $\begin{array}{l}\text { Ratio, variation } \\
\text { of NPV to X } \\
\text { variation } \\
\text { percentage }\end{array}$ & Rating \\
\hline $\begin{array}{l}\text { Annual amount of high-rise } \\
\text { construction, monetary units }\end{array}$ & 10 & 40 & 4,0 & 1 \\
\hline $\begin{array}{l}\text { Price for a square metre, } \\
\text { monetary units }\end{array}$ & 10 & 25 & 2,5 & 3 \\
\hline $\begin{array}{l}\text { Varying costs for a square metre, } \\
\text { monetary unit/m }\end{array}$ & 10 & 30 & 3,0 & 2 \\
\hline $\begin{array}{l}\text { Standing charges for a high-rise } \\
\text { building, monetary units }\end{array}$ & 10 & 15 & 1,5 & 5 \\
\hline Corporate tax rate, \% & 10 & 5 & 0,5 & 7 \\
\hline $\begin{array}{l}\text { Initial investment, monetary } \\
\text { units }\end{array}$ & 10 & 10 & 1,0 & 6 \\
\hline Project implementation, years & 10 & 20 & 2,0 & 4 \\
\hline
\end{tabular}


Table 2 - Sensitivity and predictability in high-rise construction projects

\begin{tabular}{|l|c|c|}
\hline Variable (X) & Sensitivity & Predictability \\
\hline Annual sales of high-rise buildings & High & Low \\
\hline Price per square metre & High & Low \\
\hline Recurring cost per square metre & High & Medium \\
\hline $\begin{array}{l}\text { Permanent expenses for a high-rise } \\
\text { building }\end{array}$ & Low & High \\
\hline Corporate tax rate & Low & Medium \\
\hline Initial investment & Medium & Medium \\
\hline How long it takes & Medium & Low \\
\hline
\end{tabular}

Table 3 - Matrix of sensibility and predictability of variables

\begin{tabular}{|l|c|c|c|}
\hline Predictability & \multicolumn{3}{|c|}{ Sensitivity } \\
\hline Low & I & I & I \\
\hline Medium & I & II & III \\
\hline High & II & III & III \\
\hline
\end{tabular}

For a more precise calculation of crucial issues of an investment project, it is reasonable to use the following model depicting the results influenced from within and without:

Critical values are according to (NPV):

$$
N P V=\left(Q p_{i}-V C Q-F C-\operatorname{tax}+D\right) F M 4(r, n)-I C
$$

$\mathrm{Q}$ is the annual sales;

VCQ is the summary of the variable cost;

$\mathrm{FC}$ is the fixed cost

tax is the annual depreciation;

$\mathrm{D}$ is the annual corporate tax; and

IC is the initial investment.

The structure means that the cash flow were equal to net profit adjusted to depreciation. Crucial points of an investment project and a sensitive margin (SM) will be determined for each one (Table1):

1) Loss-free sales (QBE):

$$
Q_{B E}=\frac{I C-D F M 4(r, n)}{(p-V C)(1-t a x) F M 4(r, n)}+\frac{F C}{p-V C}
$$

$\mathrm{p}$ is a unit of production

2) Loss-free unit of production (PBE):

$$
P_{B E}=\frac{I C-F M 4(r, n)[D-(1-\operatorname{tax}) F C]}{Q-F M 4(r, n)(1-\operatorname{tax})}+V C
$$

3) Loss-free variables per unit (VCBE):

$$
V C_{B E}=p_{i}-\frac{O C-F M 4(r, n)[D-(1-\operatorname{tax}) \cdot F C]}{Q \cdot F M 4(r, n)(1-\operatorname{tax})}
$$

4) Loss-free annual expenses (FCBE): 


$$
F C_{B E}=\frac{Q \cdot\left(p_{i}-V C\right)(1-\operatorname{tax})+D}{(1-\operatorname{tax})}-\frac{I C}{(1-\operatorname{tax}) F M 4}
$$

5) Maximum allowed initial investment (ICBE):

$$
I C_{B E}=\left(\left[Q\left(p_{i}-V C\right)-F C\right](1-\operatorname{tax})+D\right) F M 4
$$

6) Maximum corporate tax rate (taxmax):

$$
\operatorname{tax}_{\max }=1-\frac{I C-D \cdot F M 4(r, n)}{\left(\left[Q\left(p_{i}-V C\right)-F C\right] F M 4(r, n)\right.}
$$

7) Payoff period of an investment project (PP):

$$
P P=\frac{I C}{\left[Q\left(p_{i}-V C\right)-F C\right](1-\operatorname{tax})+D}
$$

A sensitivity calculation for a high-rise construction project is based on the following values:

The highest risk is typical of projects with a lower sensitivity margin (SM) of a certain value. Consequently, a project like this is more negatively affected within and without.

Results of an investment project are most sensitive to the price of one square metre, specific variable construction expenses, and annual sales of high-rise construction facilities. In most high-rise construction projects, the aforementioned variables are characterised by both maximum sensitivity (usually, the value of NPV per cent change ratio to the variable per cent change ratio is above 3.0) and lower foreseeability [7, p. 668]. In a situation like this, development of market-adapted pricing is a priority for marketing and finance services of the real estate developer.

Special attention should be paid to reducing variable expenses per production unit, for instance, by cutting supply prices of materials and accessories, more efficient labour management, etc. A project has a good safety margin as regards changes in fixed expenses. It helps compensate for the higher risk of changes in the price of one square metre with advertising activities aimed at increasing the probability of selling high-rise facilities. Increases in corporate tax rates, considerable changes in equipment costs and other initial investment are not very dangerous for high-rise construction projects.

\section{Conclusion}

It is therefore reasonable to use the algorithm presented in Fig. 1 in cost-benefit analysis of high-rise construction projects as a whole. Using the algorithm will simplify calculations and improve accuracy of cash flow assessment by using methods that take into account the specific nature of high-rise construction projects. The suggested algorithm considerably improves reliability of cost-benefit project analysis in high-rise construction by using an interlinked list of supplementary risk management instruments.

\section{References}

1. Guidelines for cost-benefit analysis of investment projects. Rossiyskaya gazeta, 28 June (1999) 
2. Engineering geology and geotechnical survey in high-rise construction. [Online]. Available: http://www.geoinfo.ru/includes/periodics/electronic_journal/2016/1013/ 000012240/detail.shtml (04.05.2017)

3. M. A. Limitovsky. Investment projects and real options in emerging markets (2017)

4. M. V. Gracheva, A. B. Sekerina (eds). Risk management in an investment project (2013)

5. O. V. Skotarenko. Forming of sustainable development mechanisms of an enterprise on the basis of investment efficiency assessment (2017)

6. High-rise construction: nuances and stages of building. [Online]. Available: http://stroimprosto-msk.ru/stati/stroitelstvo-vysotnyx-zdanij-nyuansy-i-etapyvozvedeniya (04.05.2017)

7. I. I. Mazur, V. D. Shapiro (eds.). Project management (2011)

8. N. A. Kazakova. Financial environment of entrepreneurship and entrepreneurial risks (2012)

9. C. Hewlett, G. Kaufmann. Strategy for Real Estate Companies (2011) 